\title{
Mastery Learning in the Classroom: Concept Maps, Critical Thinking, Collaborative Assessment (M3CA) Using Multiple Choice Items (MCIs)
}

\author{
Elham Zandvakili ${ }^{1}$, Ernest Washington ${ }^{2}$, Edmund Gordon ${ }^{3} \&$ Craig Wells $^{4}$ \\ ${ }^{1} \mathrm{PhD}$ Candidate, Language Literature and Culture in the College of Education, University of Massachusetts, \\ Amherst, USA \\ ${ }^{2}$ Professor, Emeritus, Department of Teacher Education \& Curriculum Studies, University of Massachusetts, \\ Amherst, USA \\ ${ }^{3}$ Professor, Emeritus, Department of Psychology, Yale University, USA \\ ${ }^{4}$ Associate Professor, Department of Research, Educational Measurement, and Psychometrics, University of \\ Massachusetts, Amherst, USA \\ Correspondence: Elham Zandvakili, PhD Candidate, Language Literature and Culture in the College of \\ Education, University of Massachusetts, Amherst, USA. Tel: 1-413-835-1200.
}

Received: August 5, 2018 Accepted: August 29, 2018 Online Published: September 6, 2018

doi:10.5539/jel.v7n6p45 URL: https://doi.org/10.5539/jel.v7n6p45

\begin{abstract}
M3CA is a model of mastery learning developed in a college classroom, and an acronym for Mastery, Concept Maps, Critical Thinking, Collaboration and Assessment. The M3CA model is a formative model of skill based mastery learning and assessment that produces high levels of academic achievement and empowers students with a feeling of fairness. Mastery is based on students' creation of concept maps, and the steps toward mastery include learning the skills of: critical thinking, prioritization (evaluation), individual and group synthesis, group evaluation (prioritization), and the application of multiple choice items to assess the facts, concepts and knowledge embedded in the concept maps. Multiple choice items created by and collected from teams of students are available for all to see and used in their assessment. Each step toward mastery is observable, transparent, and open to public view by the students.
\end{abstract}

Keywords: concept maps, critical thinking, collaborative assessment, multiple choice items

\section{Introduction}

The M3CA model is a skill based approach to mastery learning in college classrooms. The skills students learn are: creating concept maps, critical thinking (asking the questions what, when where, how, and why, ranking concepts in terms of importance, synthesizing, collaborating, and assessing. The goal of mastery learning is that all students are able to master the curriculum of the classroom. The key to mastery in the classroom is learning the above skills that are better known as Bloom's Taxonomy of higher order thinking. A fundamental premise of the M3CA model is that all students have the capacity to learn higher order thinking skills. Concept maps, applying critical thinking, prioritizing concepts, analysis, synthesizing, and creating multiple choice items for their assessment are skills instrumental to success in school. Teaching students to write the multiple-choice items for their own assessment is controversial. Multiple choice items are prompts to remind students of the important concepts they identified in a previous activity. This use of multiple-choice tests resembles criterion referenced testing rather than norm based assessment. The creation of multiple choice items by students is a way of identifying the content that is most important to mastering the text. As students work their way through the different activities they are exploring different kinds of higher order thinking. The creative act of self-assessment gives students a sense of ownership, fairness, and a sense of engagement in their education. Together these activities give students a transparent and clear picture of their own thinking.

\section{Background and Rational}

Mastery learning has a long history in psychology and education. Thorndike (1959), Carroll (1963) and Bloom (1974) advanced the concept of mastery as a way of closing the knowledge gap between high and low achieving 
students. These theorists were in agreement that given sufficient time and appropriate instruction all students could attain mastery of the content of instruction. Anderson and Block (1977) defined mastery learning as a philosophy of school learning and an associated set of instructional practices while at the same time embracing the idea that mastery learning and education are embedded in values about students and learning. In the 1980s this idea came under severe criticism from many critics. Slavin (1987), for example, argued that classroom data did not support the advocates of mastery. Kulik, Kulik and Banger-Drowns (1990) with a wider review of the literature reached the conclusion there was merit and evidence for mastery learning. Interest in mastery learning languished for several decades and was recently brought forward again by Gusky (2007). The concept of mastery still captures the imagination of practitioners and theorists searching for equity in education.

The M3CA approach is prompted by Edmund Gordon's (2017) view that the science of assessment has achieved considerable precision in understanding how to guide, classify hierarchically, predict, select, and certify based on developed abilities. At the same time, he noted that the science of assessment has neglected the use of tests to better enable learning as in diagnosis and possible treatment. M3CA is a methodology designed to demonstrate that assessment can facilitate the learning of critical thinking and other higher order cognitive skills. Gordon argues that the science of assessment has reached the point where soon, assessment will provide new directions to educational practice. In the past education has given direction to assessment, in the future, this relationship will be turned on its head, and the science of assessment will give new directions to education.

\section{Plan for the Paper}

The plan for this paper is to begin with a comparison of the M3CA model and the Bloom-Anderson Taxonomy of higher order thinking. This comparison shows the structure and overlap between Bloom's Taxonomy and the M3CA model. This comparison shows that the M3CA model teaches higher order thinking skills that are widely recognized as essential to higher order thinking. A literature review of the components of the M3CA model is intertwined with the procedures of the M3CA model. The review begins with the individual phase of the model in which there are the individual construction of concept maps, application of critical thinking, and prioritization. The main purpose of phase one is to ensure that all students are on the same page with regard to prior knowledge. Each week students are given a homework assignment to insure all students have a base of prior knowledge that includes constructing individual concept maps, and applying critical thinking questions.

The second or the collaborative phase that takes place in the classroom. This phase includes: collaboration, synthesis, evaluation (prioritization), and the (application) of multiple-choice items. Concept maps and evaluation (prioritization) and the construction of multiple choice items are connected by the critical thinking questions: what, when, where, how, who, and why.

The second or collaborative phase of the model includes: synthesis, the exchange of concept maps and creation of a collaborative map, the collaborative prioritization of the concepts and the collaborative creation of multiple-choice items for assessment. The final stage of the 3CA processes is mastery and a feeling of fairness and justice.

\subsection{A Comparison of the M3CA Model and the Bloom-Anderson Taxonomy}

The comparison of the Bloom-Anderson taxonomy and the M3CA model confirms the common grounds of the two processes. This is understandable because the second is built upon the first. The overall trajectory of the Bloom's (1974) research was to identify a taxonomy of knowledge and to apply that knowledge toward mastery learning. His interest in mastery learning stemmed from his determination to decrease the variation in learning among students from different backgrounds. His firm belief was that given enough time students could achieve $90 \%$ mastery of the subject matter. The M3CA builds upon both dimensions of Bloom's work incorporating a modified taxonomy of higher order thinking and extends mastery by including individual and group higher order learning processes.

Please see Table 1 that compares the M3CA model with the Bloom-Anderson Taxonomy of Higher Order Thinking. Follow the description of the stages of the M3CA model and its counterpart in Bloom-Anderson Taxonomy. A more complete discussion of the steps toward mastery is found in the reviews of critical thinking, collaborative learning, and assessment. The result is a more complete picture of the steps toward mastery. 
Table 1. Comparison of M3CA model and Bloom and Anderson`s model of learning

\begin{tabular}{|c|c|c|c|}
\hline Phase & No & 3CA using MCIs & Bloom and Anderson's Taxonomy \\
\hline \multirow{3}{*}{ Individual phase } & 1 & Using concept maps to map the concepts & Knowledge/ Remembering \\
\hline & 2 & $\begin{array}{l}\text { Applying critical thinking questions to concept } \\
\text { maps is identifying the concept, relations with } \\
\text { other concepts, and specifying the critical question } \\
\text { linking the concepts. } \\
\text { Understanding is applying more than one critical } \\
\text { thinking question to a concept. } \\
\text { See } 2.2 \text { in the review that follows }\end{array}$ & Understanding \\
\hline & 3 & $\begin{array}{l}\text { Individual prioritization of the facts and concepts } \\
\text { (Individual Evaluation) } \\
\text { See Section } 2.3 \text { in the review that follows }\end{array}$ & Application \\
\hline \multirow{4}{*}{$\begin{array}{l}\text { Collaborative } \\
\text { phase }\end{array}$} & 4 & $\begin{array}{l}\text { Synthesis: includes cognitive and social synthesis } \\
\text { in the search for commonalities, differences, gaps, } \\
\text { and pruning errors } \\
\text { See } 2.4 \text { and } 2.5 \text { in the review below. }\end{array}$ & Analysis \\
\hline & 5 & $\begin{array}{l}\text { Group prioritization takes place when team } \\
\text { members agree to prioritize concepts from most } \\
\text { important to least important } \\
\text { See } 2.6 \text { in the review below. }\end{array}$ & Evaluation \\
\hline & 6 & $\begin{array}{l}\text { Assessment: The creation of multiple choice items } \\
\text { that mark and reflect specific facts, concepts and } \\
\text { patterns of knowledge } \\
\text { See } 2.7 \text { in the review below. }\end{array}$ & Creation/synthesis \\
\hline & 7 & $\begin{array}{l}\text { Mastery: Students meet a criterion of knowledge } \\
\text { and achieve a feeling of mastery and justice } \\
\text { See } 2.8 \text { in the review below }\end{array}$ & ... \\
\hline
\end{tabular}

The first stage of the Bloom-Anderson Taxonomy is knowledge and remembering. In the M3CA model this is also the same stage of constructing concept maps that includes concepts, facts and behaviors that are the basic elements in the model.

The second stage in the Bloom-Anderson Taxonomy is the comprehension and understanding of knowledge. There are many ways of knowing about the world. Three forms of knowledge are explicit in the title, M3CA, concept maps highlight visual knowledge while critical thinking emphasizes cognitive knowledge. During each of these stages students learn to apply the critical thinking questions of "what, when, where, who, how and why". As students apply more than one question to a concept, they deepen their critical thinking. The result is the pattern processing of the concepts, facts, and behaviors described in stage one. The learners are pattern processors searching for patterns among concepts, events, ideas, feelings, behaviors, and actions. Examples of pattern processing include: thinking, language, cognitive maps of the physical environment, landmarks, predators, resources, faces, gestures and sounds of language, reasoning and rapid decision making. Pattern processing underlies the different ways of knowing about the world.

Stage 3 of the Bloom-Anderson Taxonomy is the application of knowledge. The contrasting stage in the M3CA model is the individual evaluation and prioritization of the concepts from the most to the least important. The Taxonomy's focus is on the individual development of higher order thinking while stage three in the M3CA model is the application of the evaluative mind set as students evaluate concepts from the most to least important.

Stage 4 in the M3CA model is synthesis, the beginning of the collaborative phase, this activity begins with the exchange of concept maps. Students exchange concept maps and explore their commonalities, differences, the gaps in their respective maps followed by the pruning of errors and extraneous knowledge. During collaboration students shift from individual to social knowledge and gain insights into their own thinking and the thinking of other students. Stage 4 in the Bloom-Anderson Taxonomy is analysis, creating something new from different information. Students engaging in synthesis in the M3CA model are also engaged in analysis of commonalities, differences and gaps in knowledge while at the same time making something new.

Stage 5 is prioritization in the M3CA model and teams of students collaboratively prioritize the concepts. They use their evaluative mindsets to rank the concepts in hierarchical order from the most to the least important. 
Stage five in the Bloom-Anderson Taxonomy is evaluation. In the Bloom-Anderson Taxonomy evaluation is judging the value of the material but in M3CA model it is judging and prioritizing not only the concepts but also the critical thinking about concepts.

Stage 6 is the creation and application of the multiple-choice items based on the prioritized concepts. Multiple-choice items deepen the understanding of concepts. Multiple choice tests include three parts: the stem (hypothesis), the data, and the conclusion. When students identify the concepts to be examined via multiple-choice items, they specify the knowledge to be learned. The items thus mark the prioritized knowledge, and this transforms multiple-choice items from norm based items to criterion referenced items. The students not only create the items, but these same items are available via the class website to prepare for and use in the assessment of their achievement. Using student created items as the basis for assessment is a transformative moment for students, and they embrace the opportunity to study and think about the items for their assessment.

Stage 7 does not exist in the Bloom-Anderson Taxonomy. In the M3CA model stage 7 is a revelatory moment for students as they complete the steps toward mastery and achieve a feeling of control, power and justice in their learning. This stage is compatible with the thesis by Bloom (1974) and Carroll (1963) that mastery learning is a sequential process, and competence is attained after a series of learning experiences that may take days, weeks, months, or even years. Bloom's definition of mastery was an attainment of $90 \%$ on the criterion test. The M3CA model adopts the same approach and the standard as proposed by Bloom.

A feeling of justice and fairness empower students as they achieve mastery of the activities of classroom learning. The feeling of justice is a blend of positive emotions such as love, happiness, satisfaction, confidence that replace anxiety, disappointment, and fear in the classroom. Over time as students achieve success in the classroom, the positive emotions replace the negative emotions. Feelings come first in justice in the daily round of activities, and only later are students able to cognitively appreciate the specific cognitive skills they are learning. During the course of the M3CA process, knowledge is first an individual attainment and then a group process. Through collaboration individual knowledge is shared and transformed into group knowledge. As a consequence, knowledge is shared and distributed throughout the group rather than in the head of a single individual. The visualization of knowledge through concept maps and critical, higher order thinking leads to mastery that opens the door for students to see their thinking unfolding on paper. In traditional classrooms thinking is routinely made into a mysterious process to which only a few have access and high achievement. The opposite is true with M3CA, thinking and cognitive strategies are pictures and maps that students, create, share, question, critique and use in problem solving. Creating a concept map and multiple-choice items brings the mysterious processes of learning and thinking into open view.

\subsection{Concept Maps: The Beginnings of the Mastery of Facts, Concepts and Higher Order Thinking}

\subsubsection{History and Theory}

The idea of concept maps originated at Cornell University in 1984 by Bill Trochem and a doctoral student, Dorothy Torre (Donnelly, 2017), and by Novak and Gowin the same year. Concept maps are a form of visual or picture thinking with great educational potential. Picture thinking is fast, automatic, effortless, often unconscious, and brings images to mind, spreading neural activation, enabling the individual or group to respond more easily than before. Concept maps are a portal into visual thinking. When we understand something, we say that we "see" it. We arrive at the solution to a problem through "insight." To better communicate our ideas, we aim to make them "clear." Such metaphors likening cognitive processes to visual experiences are so pervasive as to suggest a close correspondence between how we think about and how we see the world (Fan et al., 2015).

Concept maps are situated in the visual thinking tradition in which signs on maps represent knowledge in space. These maps represent what Jonassen (2000) calls mind tools. Mind tools are cognitive amplification and reorganization tools which exceed the limitations of the human mind by doing things more accurately and at a higher speed, and extend the use of other mechanical tools. Mind tools are generalizable from one setting to another engaging and facilitating cognitive processing. They help learners think for themselves and make connections between concepts and create new knowledge.

Concept maps organize, plan and display information over a wide variety of knowledge domains. Learners and educators use concept maps to scaffold knowledge and display the structure and organization of knowledge. The resulting map makes explicit and transparent the way the mind works. Here-to- fore, the workings of the mind have not been open to public view. The use of mental maps reveals to students, ourselves and others, the workings of the mind.

A meta-analysis of concept maps by Nesbit and Adesope (2006) is a theoretical and practical analysis of the 
existing experimental research and a guide to future research and inquiry. They succinctly begin with the observation that concept maps or knowledge maps are diagrams that represent ideas as node link-assemblies, and there has been a steady increase in the number of published studies over the past thirty years. Concept maps are considered as a good tool to assist the instructor to organize knowledge and an appropriate tool for students to notice the important concepts in different materials and knowledge structures (Novak, 1991; Jonassen, 2000; O'Donnell, Dansereau, \& Hall, 2002). Please see Figure 1 for an example of a concept map in which critical thinking is applied to the links between concepts.

Concept maps is an empirical methodology that combines visual and linguistic thinking. Text materials are transformed into images through using concept maps. Picturing knowledge with linguistic facts and concepts permit the scaffolding of critical thinking that crosses and connects individual prioritization, synthesis, evaluation, application and mastery in the M3CA model. The picturing of thinking and the changes in picture thinking are a methodological and empirical advance as well as a source of psychological insight to the learner. From an empirical point of view, it is possible to picture critical and higher order thinking while from a subjective point of view learners are able to recognize and see their own thinking.

Critical thinking, synthesis, and evaluation are different forms of thinking in the M3CA model that result in different pictures of thinking. The use of concept maps makes it possible and feasible to measure as well as picture the different forms of higher order thinking. The formative measurement of the different forms of thinking using concept maps makes possible the recognition and measurement of changes in thinking over time. The empirical measurement of changes in higher order thinking is a useful advance in methodology. The learner's subjective experience of the picturing of thinking is also an important consequence of the use of concept maps. Students are told repeatedly that it is important to improve their thinking or simply to start to think. The use of concept maps makes it possible to chart the improvement in the thinking of students. Many students have absorbed the criticisms that they do not know how to think. Concept maps make it possible to show students a picture of their thinking and how to improve their thinking.

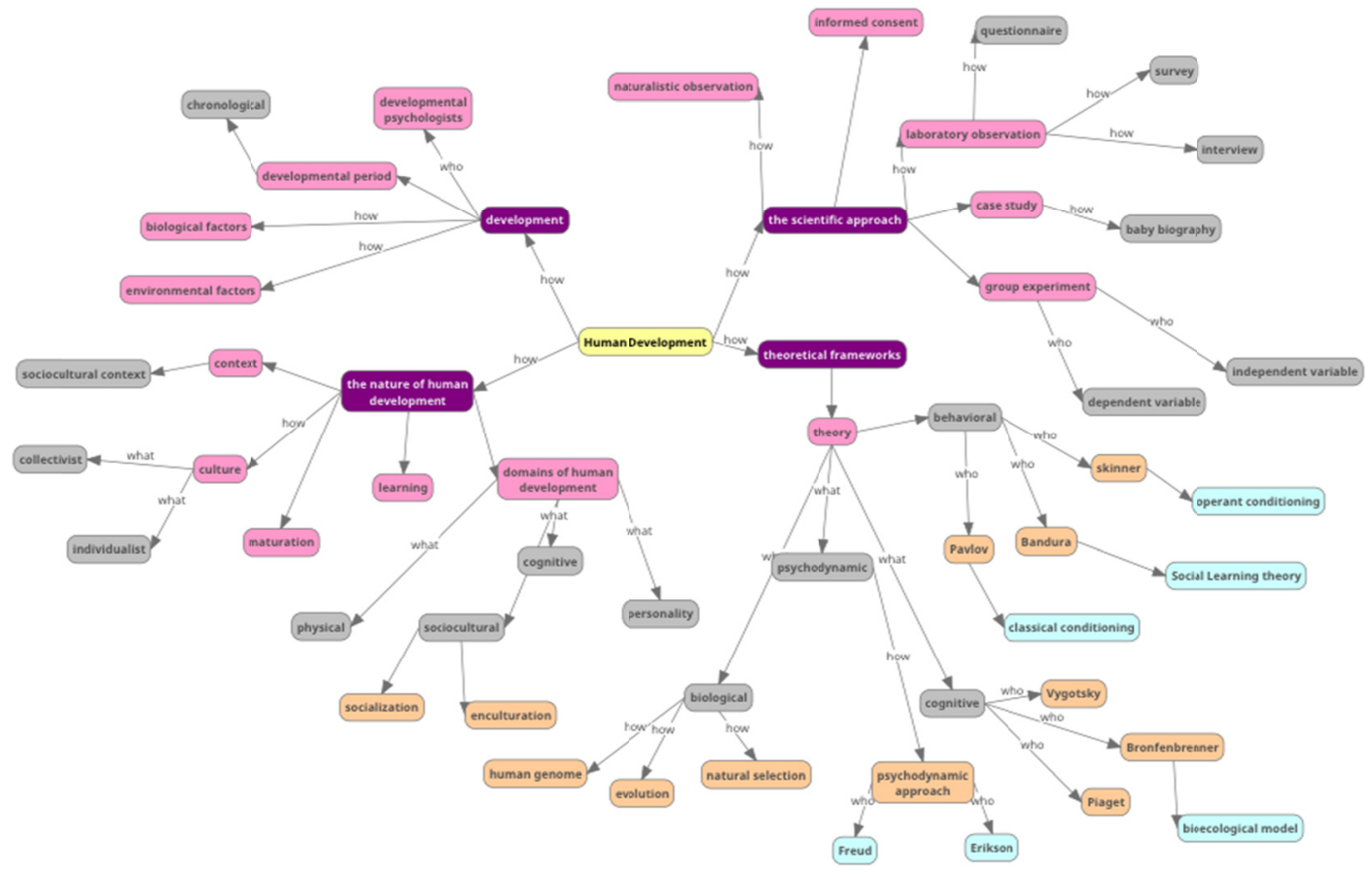

Figure 1. A concept map with critical thinking links

\subsection{Applying the Critical Thinking Questions of Why, What, When, How, Where, and Who}

Critical thinking is defined as applying the questions of "what, when, how, who, where, and why" to a text. Asking questions is part of the natural history of what it is to be human, and today using questions and answers is a part of everyday conversation. Homo-Sapiens crossed an evolutionary threshold when one said to another, "Where did you find and kill the gazelle, his clan member answered, Go south to the lake near the mountain, the 
gazelle will come to you when the sun begins to set. Thus, was the hypothetical beginning of the sharing of information through questions and answers was an evolutionary adaptation.

The critical thinking are used three different times in the 3MCA model: 1) in labeling the links between concepts in the concept map, 2) in the collaborative creation of a shared map, and 3) in the creation of multiple choice questions by students. The three applications provide students with a facility in the application and understanding of the flexibility and power of asking and answering questions. The application of the critical thinking questions to the links in the individual concept maps is the first step is to making students aware that critical thinking is something they do during the activities of the day. Applying critical thinking questions is a blend of visual and verbal thinking? Translating a written text into a concept map is visual thinking. Some students find the visualization of the concepts to be a very helpful experience while others do not find it helpful. A simple counting of the concepts and their links is a gauge of critical thinking by students.

A social synthesis of knowledge occurs with the sharing of concept maps in the collaborative phase. During this phase students exchange concept maps and discuss the differences between their maps. As they converse about the differences in their maps, they create a new map that synthesizes the two maps. From these discussions students create a new map and they collaboratively agree upon the critical thinking questions that link their shared map. The application of critical thinking to a shared project is a conversation about thinking critically.

The creation of multiple choice items is the third use of the critical thinking questions. The constructing of multiple choice items is an act of collaborative creativity, and it occurs after students have collaboratively prioritized the concepts from most to least important. Multiple-choice items begin with the critical thinking skills of "why, who, when, where, how, and what. There is a conceptual fit between the questions and answers with multiple-choice items. The method of multiple-choice tests is concerned with arriving at the right answer using the dialectic of question and answer. The application of the multiple-choice format to the critical thinking questions introduces a systematic approach to the teaching of critical thinking.

Thinking skills are taught in the M3CA model as students use critical thinking individually and collaboratively. The differences between individual and collaborative thinking resembles the distinction made by Kahnemann (2011) of fast and slow thinking. Fast thinking is unconscious, frequent, automatic and emotional. Slow thinking is effortful, conscious, deliberate, and infrequent. Kahnemann identified the biases that were associated with the two different systems of thinking. Students are thinking fast when they apply critical thinking questions to their individual concept maps. Critical thinking is slow thinking from a temporal perspective because students have conversations about the differences in their concept maps. From the dialectical conversations students recognize and apprehend the differences in the way the minds of their partners work. They are shifting from the individual to the collaborative approach to thinking, and in doing so they are deepening their knowledge of the concepts. Thinking slows down even more when students collaboratively create multiple-choice items using multiple choice questions they have created.

\subsection{Individual Prioritization and Value Judgments}

The individual phase of the M3CA model includes the creation of concept maps, the application of critical questions, and the prioritization of the concepts. Prioritization is an evaluative process in which students make value judgments about the importance of the different concepts in their concept maps and critical thinking. Prioritization is a series of value judgments along a continuum from most important to least important. The stakeholders in this model are students who share similar goals. In many studies involving concept maps and critical thinking, the stakeholders do not share the same values, goals, visualizations and patterns of thinking or priorities. Concept maps are a useful way of examining the visual representations of the differences in thinking between different stakeholders. Concept maps are thus a useful way of identifying and measuring the importance of facts and concepts to different stakeholders.

\subsection{The Collaborative Phase of M3CA}

The collaborative phase of the M3CA model marks the moment when knowledge is transformed from an individual transaction into dialogues with other minds. The latter is a dynamic process of knowledge synthesis which begins when students exchange their individual concept maps with a team member. Synthesis is a label for the dialogue between team members in which they compare, debate, and reach resolutions. The evaluation or prioritization, the next step begins when students collaboratively make value statements and rank the concepts from most to least important. The assessment step begins when students collaborate and use the prioritized concepts and the critical questions to create multiple-choice items. These social and collaborative steps empower students and lead them toward mastery. 
Collaboration is derived from the Latin "collaborare" and means to work together. Andrews and Rapp (2015) in their review of the psychological and cognitive science literature make clear that collaboration has its own unique benefits, costs, and challenges in facilitating learning and memory. The benefits of collaboration include social, emotional and psychological well-being of the participants. Collaborative activities support achievement, problem solving, positive attitudes toward subjects, self-esteem, positive peer relations, when compared to individual and competitive activities. The other benefits include providing opportunities for the elaboration of knowledge, inquisitive and constructive dialogue, the co-construction of ideas, the resolution of conflicting knowledge and better information recall. Dialogue within groups provides articulate explanations, strengthen existing knowledge structures and encourages the reorganization of knowledge, helps acquire new information and correct misunderstandings. The benefits to memory of collaboration are as beneficial as learning. Group members are exposed multiple times to more information than a person encounters as an individual. As learners encode more information during an activity, recall increases when compared to independent recall. Andrews and Rapp use the term "error-pruning" to describe the process by which individuals engage in discarding or discounting particular kinds of information. One of the more salient benefits of collaboration in learning is that the process makes gaps in knowledge more salient. The discomfort generated by the collaboration helps reconcile conflicts and facilitate critical thinking. There are also costs associated with collaboration; Group members while collaborating can also provide unrelated or inaccurate information, and this information can be accepted, endorsed, and incorporated into existing cognitive structures.

Task complexity is an important variable in understanding collaborative learning in groups. Students in groups solving problems of high complexity are more successful than students working alone. Not surprisingly students working alone on a low complexity task do better than students in groups. Low complexity tasks include activities which can be retrieved while high complexity tasks require retrieval and also involves relating that information to solving a problem.

Nesbitt and Adesope (2006) found that creating concept maps in a group and having time to work individually produced stronger effects than working alone. This, of course, is not surprising because it is expected that collaborative learning is more effective than individual learning. The M3CA model includes an individual phase of constructing concept maps and an extended collaborative phase that includes synthesis, prioritization and assessment. The collaborative steps of the synthesis of concept maps, the prioritization of concepts, and the construction of multiple-choice tests are independent and separate applications of concept maps and are mutually reinforcing. Schroeder, Nesbit, Anguiano and Adesope (2017) found that using concept maps over time increased the effectiveness of the learning and retention of the concepts. The M3CA combines individual and group construction of concept maps over an extended period of time. This combination results in a more powerful educational tool.

\subsection{Synthesis: the Collaboration and Sharing of Knowledge}

The synthesis of concept maps is the first step of a collaborative process that also includes prioritization (evaluation), application and mastery. Synthesis begins when students exchange concept maps they have constructed using the critical thinking strategies and create a new map that represents their shared thinking. The creation of a new synthesis involves the searching for and identification of commonalities, differences, gaps in their knowledge, and the pruning of errors.

The first step in the synthesis process is the identification of common and shared patterns of knowledge. There are inevitable clusters of knowledge that emerge during the creation of individual concept maps with critical thinking. The agreement between members can be gauged by simply counting the number of concepts and uses of the "wh questions": "what, how, when, where, who and what" in their individual maps. It follows that these agreements are represented in the new shared maps. The clusters of shared concepts are the central features of the shared knowledge of the group. These clusters of knowledge reveal the theoretical state of knowledge in the minds of students. This is a pivotal step because for the first time, students see the workings of the mind of another student. Students are stakeholders with the same values and purposes, and thus there is expected to be agreements between students.

The second step in the synthesis process is the identification of the differences between team members in their construction of individual concept maps. Students begin the discussion of the differences in their maps, and this is also a conversation about how students think differently. The purpose of identifying differences between the maps is to negotiate which differences are to be incorporated into the new maps. The differences between student maps are gaps in knowledge. The student/investigators ask themselves why there is a disparity and report it. The differences between the maps of individual students are sometimes simply a matter of errors. One of the 
major benefits of sharing the differences between maps is to eliminate errors in the shared maps.

Concept elaboration is the third and perhaps the most beneficial step in the synthesis process. Elaboration is the applying of multiple critical thinking questions to the same concept or knowledge. A concept that was previously described as a what question is explored using the critical thinking strategies of "what, who, why, where, when and how". The elaboration of concepts deepens the understanding of knowledge and the critical thinking skills from multiple perspectives. Understanding has been an elusive concept in the processes of thinking. Wittgenstein defined understanding as grasping the whole and knowing your way around the language game. It is a neat fit to combine the concept of understanding with elaboration. Understanding is redefined as understanding the whole and using critical thinking to find the ways around concepts. (Ackerman, 1992)

\subsection{Collaborative Prioritization}

Value judgments are threaded throughout the M3CA model as is the case with all research endeavors. Prioritization is the stage in which the values of the M3CA model are made explicit. While values are threaded throughout the model, they emerge clearly in this stage. The first steps in the valuation process begins with the embracing of the Bloom-Anderson Taxonomy that ranks knowledge from facts to increasingly complex forms of knowledge such as evaluation, creation and application. Bloom and Anderson recognized other forms of knowledge other than cognition, nevertheless, the separation of cognition, affect, and artistic knowledge is a value judgment. The M3CA model follows Bloom-Anderson for pragmatic reasons. A consideration of these other forms of knowledge is essential, nevertheless it is important to stay focused upon the explication of the cognitive, and leave these other issues for another time and for others to consider.

The valuation of knowledge in the M3CA model is reinforced by the role of the stakeholders in the assessment process. The stakeholders in the M3CA model are students and teachers. While the focus is upon the students, the teachers are also stakeholders and beneficiaries of the model. The empowering of students is a statement about the value and importance of students in the evaluation and educational process. Too often in educational evaluation the values and interests of the students are neglected. The M3CA model places students at the center of the evaluation process by empowering them to construct the means of their evaluation and the improvement of their achievement. Teachers benefit from the empowering of students and their improved achievement in very clear ways.

The valuing of students is made explicit in their collaborative prioritizing of the concepts that are the subject of inquiry. Team prioritizing is an activity in which team members prioritize the concepts from their shared concepts maps. This is an exercise in valuation in which students reach an agreement on ranking the concepts from the most to the least important. The constructed dialogue between students is an example of thinking out loud, and it lends itself to think aloud protocols. The activity of thinking out loud affords students the opportunity to verbalize and describe their visual and verbal thinking. New meanings are created as students create their shared maps and priorities. One of the outcomes of the group prioritization process is a hierarchy of concepts that will be used to specify the concepts in the construction of multiple-choice tests. The prioritization procedure is not restricted to the creation of multiple-choice tests but can be applied to essay questions, true false questions and other forms of assessment.

Prioritization and the valuation of concepts occur at the individual and the collaborative phases of the M3CA process. Comparing the data from the individual and the collaborative phases provides an indicator of changing values as a result of the learning processes. The stakeholders in the M3CA model are students and share a similar set of values. However, if the prioritization is applied in situations where the stakeholders have different values, the comparisons will reveal larger shifts in values. Prioritizing or ranking lends itself to multidimensional scaling, a powerful statistical analysis, in which it is possible to visualize individual and group differences in valuations. Individuals and groups construct priority hierarchies, the similarities and differences between the hierarchies is a picture of the differences between individuals and the group. Repeated measures over time show changes in individual and group values.

\subsection{Assessment: the Creation of Multiple Choice Items}

Assessment is the third collaborative phase of the M3CA process. The multiple-choice items used in the model look the same as traditional multiple-choice tests but looks are deceiving. The students engaged in the M3CA process are creating something new, they are creating multiple-choice criterion referenced items. Multiplechoice tests are not new, but students creating multiple choice criterion referenced tests is new. M3CA redefines the form and function of multiple-choice tests. The form of a test is its appearance and its functions are the processes used to create the tests. According to Farhady, et al, (2007), function includes three factors: the characteristics of the examinee, specific purpose of the test and scope of the test. The M3CA model with 
students creating multiple choice items changes the functions of the test while retaining the same form they have had over the past century.

The characteristics of the examinee and the examiner are now the same. Students are in charge and control the creation of knowledge and the assessment process. They are acting as student and assessor. They are in a position of power. This is a pivotal moment in the M3CA model because this realignment dismantles the traditional hierarchical structures of classroom learning. The function of the multiple-choice tests in the M3CA model is to assess mastery of a body of knowledge, improve classroom learning, teach critical thinking skills, and to empower students to take the responsibility to create multiple choice items that will be the basis of the assessment of their classroom achievement.

The M3CA model repurposes traditional multiple-choice items from a norm-based instrument to a criterion-referenced item. The mastery and assessment of a body of knowledge is the aim of the M3CA model of assessment and not the ranking of students. The boundaries and content of this knowledge are in the concept maps students create. Multiple-choice items are knowledge markers of the content and the structures of knowledge. The larger the number of multiple-choice items the more complete is the coverage of the knowledge. The knowledge indicated ranges from the simple declarative knowledge to complex higher order thinking, and students are the creators of the knowledge indicators designed to understand the content and the structure of knowledge.

The individual item is a knowledge indicator and the experimental unit in the M3CA model. This unit consists of the stem and its alternative explanations with the stem being redefined as two or more events and the alternative explanations as possible events. The problem posed to the learner is how to make connections and find patterns between the events in the stem and the alternative event(s). Applying the critical questions of what, when, where, how and who is a way of exploring the connections between stem and the alternative explanations. Critical thinking is the bridge between the statement of the problem in the stem and the alternative explanations. The application of critical thinking questions to the text of the stem is a search for patterns of knowledge by the students. As students examine the text of the item, they are searching for patterns that coincide with their critical thinking strategies.

Students learn to construct multiple-choice items. The specification of the stem as involving two events and the alternatives as involving one or more events guides students in constructing multiple-choice items. Applying the critical thinking question enriches critical thinking and the construction of multiple-choice items. The items are keyed to the prioritized concepts, and mark the concepts that are most important. Students can now see their thinking, they show it to others, get feedback, make improvements in their thinking and demonstrate that their critical thinking is a dynamic process.

\subsection{Mastery}

Mastery is a feeling of justice and fairness and the goal of the M3CA model of classroom learning. The M3CA is also a set of practices and a philosophy designed to teach thinking skills and to achieve mastery of a text in a college classroom. The model reconstructs the concept of mastery learning by focusing upon teaching cognitive thinking skills while retaining the belief that all students are capable of achieving mastery of the content of instruction. The set of practices advanced by the M3CA model include the construction of concept maps; the application of the critical thinking questions of what, when, why, where, who, and how questions; evaluation and prioritization, group collaboration and synthesis and the creation of multiple choice items by students to evaluate their progress toward mastery. Each activity is designed to teach a particular thinking skill, and students are motivated and engaged by the idea that they have the thinking skills and a pathway to achievement and mastery.

The philosophy of mastery learning begins with Thorndike (1959), Carroll (1963) and Bloom (1974) who proposed the concept of mastery as a way of closing the knowledge gap between high and low achieving students. The idea that all students could achieve mastery in the classroom was a radical idea at the time. It was taken for granted in the 1950s, 1960s and 1970s that the gap in achievement between whites and people of color was due to hereditary factors. Anderson and Block (1977) defined mastery learning as a philosophy of school learning, an associated set of instructional practices, and the idea that mastery learning and education are embedded in values and circumstance. The researchers above did not consider the possibility students could be taught the necessary cognitive skills to achieve mastery in the classroom.

The M3CA model of mastery learning teaches thinking skills as the pathway to the achievement of mastery. The thinking skills are the same as those identified by Benjamin Bloom in his classic, Taxonomy of Higher Order Thinking. Bloom's Taxonomy is a useful comparative standard for the M3CA model because the taxonomy has stood the test of time and its successors remain the way in which researchers organize and research the different 
forms of thinking. The M3CA model teaches the skills of analyzing, organizing, synthesizing, and evaluating while using the critical thinking skills of: what, when, why, who, where and how. The M3CA model uses multiple-choice items to assess mastery learning by having students create test items, and using a random sample of these items for their assessment. Placing students at the center of assessment and empowering them to create their own assessment turns the use of multiple choice tests upside down. In the process of learning to create multiple choice tests students learn the thinking skills of deduction and induction.

The achievement of mastery is the moment when students have learned to play the language game, and the practice of cognitive skills leads to mastery and a feeling of justice. The idea that justice is a feeling is not the standard view nevertheless it is a view that is receiving increased attention. The m3CA model shifts the focus from the teacher to the student in the classroom. With students at the center of the instructional process, it is therefore important classroom $\mathrm{c}$ to consider the students emotional perspective in the classroom. Mastery of the activities in the classroom leaves students with feelings of confidence, a sense of agency, and the idea there is justice in the classroom.

\section{Conclusions}

The M3CA is a skill-based model of mastery classroom learning that accomplishes three important goals: 1) supports mastery learning as a plausible educational theory, 2) teaches critical and higher thinking, 3) and empowers students through educational fairness and justice. The M3CA model is a step toward the inclusion of mastery learning into policy conversations about the improvement in the education of poor children. It is a model of classroom learning that leads to mastery in the classroom. The model is practical and can be instituted in a classroom by classroom-basis. Elliott (2017) claims that the implementation of the M3CA model is a matter of volition. Mastery learning is a plausible approach to instruction that is available to all teachers and students.

The M3CA model teaches the critical and higher order thinking skills that are the steps toward mastery in the classroom. The initial comparison of the M3CA model with the Bloom-Anderson Taxonomy was made to point out that the critical skills taught in the M\#CA are widely accepted as essential skills in higher order thinking. The model uses concept maps, critical thinking, evaluation, synthesis, collaboration and the application of criterion-based multiple-choice tests to assess achievement. The methodological shifts to concept maps, the integration of critical thinking in the curriculum, and application of criterion based multiple choice tests generated by students are the transparent shifts and innovation in the M3CA model of assessment. Criterion based multiple choice assessment is a natural fit with the aims of mastery learning, and provides a solid empirical grounding for the assessment of mastery learning. Using student generated multiple choice tests shifts the power dynamics in classrooms and empowers students. There is reason for optimism here because this approach to mastery is skill based and not simply depended upon the acceptance and support of students.

The fairness or justice dimension of the M3CA is one of its most distinctive and important features. Justice is a feeling that students achieve as they take the steps toward mastery. The structures of the M3CA, concept maps, critical thinking, and collaboration transform evaluation into a methodology that values diversity by making thinking and assessment transparent and available to all. Thinking has long been shrouded from public view in most assessments of student achievement. In traditional classrooms students receive information about failures or successes with no explanation of the success or the failure. The M3CA model changes that dynamic and provides students with a new transparency that allows them to see and change their thinking in the present, and opens paths for achievement in the future.

\section{References}

Ackerman, R. C. (1992). Wittgenstein's City, Amherst, U. Massachusetts Press. The Philosophical Review, 101(2). https://doi.org/10.2307/2185555

Anderson, L. W., Krathwohl, D. R., Airasian, P. W., Cruikshank, K. A., Mayer, R. E., Pintrich, P. R., Raths, J., \& Wittrock, M. C. (2010). A Taxonomy for Learning, Teaching, and Assessing: A revision of Bloom's Taxonomy of Educational Objectives. New York: Pearson, Allyn \& Bacon. https://doi.org/10.1080/00461520903433562

Andrews, J. J., \& Rapp, D. N. (2015). Benefits, costs, and challenges of collaboration for learning and memory. Translational Issues in Psychological Science, 1(2), 182. https://doi.org/10.1037/tps0000025

Ausubel, D. P. (1966). Meaningful reception learning and the acquisition of concepts. In Analyses of concept learning (pp. 157-175). https://doi.org/10.1016/b978-1-4832-3127-3.50015-8

Bloom, B. S. (1980). The new direction in educational research: Alterable variables. The Journal of Negro Education, 49(3), 337-349. https://doi.org/10.2307/2295092 
Bloom, B. S. (1984). The 2-sigma problem: The search for methods of group instruction as effective as one-to-one tutoring. Educational researcher, 13(6), 4-16. https://doi.org/10.3102/0013189x013006004

Bloom, S. E. (1974). Current knowledge about the avian W chromosome. BioScience, 24(6), 340-344. https://doi.org/10.2307/1296739

Carroll, J. B. (1963). A model of school learning. Teachers college record. Retrieved from http://garfield.library.upenn.edu/classics1982/A1982NF37300001.pdf

Donnelly, J. P. (2017). A systematic review of concept mapping dissertations. Evaluation and program planning, 60, 186-193. https://doi.org/10.1016/j.evalprogplan.2016.08.010

Fan, Y., Xu, Q., Guo, Y., \& Liang, S. (2015, July). Visualization on agglomerative information bottleneck based trajectory clustering. In Information Visualisation (iV), 2015 19th International Conference on (pp. 557-560). IEEE. https://doi.org/10.1109/iv.2015.98

Farhady, H. J., \& Jafarpur, A. J. A., \& Birjandi, P. (2007). Testing language skills: From theory to practice.

Guskey, T. R. (1983). Clarifying time related issues. Outcomes, 3(1), 5-7.

Guskey, T. R. (1987). Rethinking mastery learning reconsidered. Review of Educational Research, 57, 225-229. https://doi.org/10.3102/00346543057002225

Guskey, T. R. (2007). Closing achievement gaps: revisiting Benjamin S. Bloom's "Learning for Mastery". Journal of Advanced Academics, 19(1), 8-31. https://doi.org/10.4219/jaa-2007-704

Halpern, D. F. (1998). Teaching critical thinking for transfer across domains: Disposition, skills, structure training, and metacognitive monitoring. American psychologist, 53(4), 449. https://doi.org/10.1037//0003-066x.53.4.449

Jonassen, D. H. (2000). Computers as mindtools for schools: Engaging critical thinking. Prentice Hall. https://doi.org/10.2190/p2ft-x9he-6ud5-dynj

Kahneman, D., \& Frederick, S. (2007). Frames and brains: Elicitation and control of response tendencies. Trends in cognitive sciences, 11(2), 45-46. https://doi.org/10.1016/j.tics.2006.11.007

Kane, M., \& Trochen, W. M. K. (2007). Concept maps for planning and evaluation. Sage, Thousand Oaks, Calif. https://doi.org/10.4135/9781412983730

Kant, I., \& Wood, A. (1996). Groundwork of The metaphysics of morals (1785). In M. Gregor (Ed.), Practical Philosophy (The Cambridge Edition of the Works of Immanuel Kant, pp. 37-108). Cambridge: Cambridge University Press. https://doi.org/10.1017/cbo9780511813306.007

Kirschner, P. A., \& Erkens, G. (2006). Cognitive tools and mind tols for collaborative learning. J. Educ. Computing Research, 35(2), 199-209. https://doi.org/10.2190/r783-230m-0052-g843

Kohlberg, L. (1973). The claim to moral adequacy of a highest stage of moral judgment. The Journal of Philosophy, 70(18), 630-646. https://doi.org/10.2307/2025030

Kohlberg, L. (1981). The philosophy of moral development: moral stages and the idea of justice. Publisher missing. https://doi.org/10.1017/s0360966900024452

Kulik, J., Kulik, C. L. C., \& Banger-Drowns, P. (1990). Is there better evidence on mastery learning. Review of Educational Research, 60(2), 303-307. https://doi.org/10.2307/1170614

Mattson, M. P. (2014). Superior pattern processing is the essence of the evolved human brain. Frontiers in Neuroscience, 8 .

Meroe, A. S. (2014). Democracy, meritocracy and the uses of education. The Journal of Negro Education, 83(4), 485-498. https://doi.org/10.7709/jnegroeducation.83.4.0485

Nesbit, J., \& Adesope, O. O. (2006). Learning with concept and knowledge maps: a meta-analysis. Review of Educ. Research, 76(3), 413-448. https://doi.org/10.3102/00346543076003413

Novak, J. (1991). Clarify with concept maps. The Science Teacher, 58(7), 44.

Novak, J. D., \& Cañas, A. J. (2008). The theory underlying concept maps and how to construct and use them. Retrieved from http://cmap.ihmc. us/docs/theory-of-concept-maps

Novak, J. D., \& Gowin, B. (1984). Learning how to learn. Oxford, UK: Cambridge University. https://doi.org/10.1017/cbo9781139173469 
Novak, J. D., \& Gowin, D. B. (1984). Learning how to learn. Cambridge University Press. https://doi.org/10.1017/cbo9781139173469

O'donnell, A. M., Dansereau, D. F., \& Hall, R. H. (2002). Knowledge maps as scaffolds for cognitive processing. Educational psychology review, 14(1), 71-86. https://doi.org/10.1023/a:1013132527007

Piaget, J. (2002). Judgement and reasoning in the child. Routledge. https://doi.org/10.4324/9780203207260

Schroeder, N. L., Nesbit, J. C., Anguiano, J., \& Adeaope, O. O. (2017). Studying and constructing concept maps: A meta-analysis. Educational Psychological Review, 1-25. https://doi.org/10.1007/s10648-017-9403-9

Slavin, R. E. (1987). Mastery Learning Reconsidered. Review of Educational Research, 57(2), 175-213. https://doi.org/10.3102/00346543057002175

Slavin, R. E., \& Karweit, N. L. (1984). Mastery learning and student teams: A factorial experiment in urban general mathematics classes. American Educational Research Journal, 21, 725-736. https://doi.org/10.3102/00028312021004725

Solomon, R. C. (1990). A passion for justice: Emotions and the origins of the social contract. Salem Press, Ipswich, Ma. https://doi.org/10.5840/bemag19904660

Solomon, R. C. (1994). The passions: emotions and the meaning of life. Hackett Publishing Co., Indianapolis.

Thorndike, R. L. (1976). Reading comprehension education in fifteen countries: International Studies in Evaluation. New York: Wiley. https://doi.org/10.1086/445874

Trochen, W. N., \& Linden, (2017). Introduction to Special Issue on concept maps. Evaluation and Program Planning, and Evaluation, 60, 166-175. https://doi.org/10.1016/j.evalprogplan.2016.10.006

Von Wright, G. H. (1971). Explanation and understanding. Ithaca, New York, Cornell U. Press.

\section{Notes}

Note 1. In an earlier pilot study, the authors created a manual that guided the training of students in the uses of concept maps, critical thinking, collaboration and the creation of multiple choice tests.

\section{Copyrights}

Copyright for this article is retained by the author(s), with first publication rights granted to the journal.

This is an open-access article distributed under the terms and conditions of the Creative Commons Attribution license (http://creativecommons.org/licenses/by/4.0/). 